\title{
Oats, more than just a whole grain: an introduction
}

\author{
Roger Clemens $^{1 *}$ and B. Jan-Willem van Klinken ${ }^{2}$ \\ ${ }^{1}$ School of Pharmacy, International Center for Regulatory Science, University of Southern California, \\ 1540 Alcazar Street, CHP 140, Los Angeles, CA 90033, USA \\ ${ }^{2}$ Quaker Oats, Subsidiary of PepsiCo, Inc., Room 220, 617 W Main Street, Barrington, IL 60011, USA \\ (Submitted 2 October 2013 - Final revision received 1 August 2014 - Accepted 6 August 2014)
}

\section{Abstract}

In May 2012, an oats workshop was held in New York to convene a group of international experts to discuss the implications and applications of oats relative to human health. These diverse experts represented disciplines including, but not limited to, epidemiology, food regulation, nutrition and food science, grain breeding and plant genetics, food processing, medicine and public-health policy. This ensuing series addresses three important aspects pertinent to oats: a brief overview of the dynamics of oats; the spectrum of established and emerging research in agriculture and health; and the options and opportunities for future applications of oats that extend beyond dietary fibre. Oats have many unique chemical properties, potential health benefits, agricultural challenges and nutrition-policy opportunities - but global production of oats appears to be falling. This is occurring despite contemporary research in the development of drought and infestation resistance and climate-adaptive cultivars and assessments of oats' unique components (such as dietary fibre, lipids, $\beta$-glucan and avenanthramides) that may contribute to health benefits. This suggests that oats represent a promising grain in the whole-grains landscape. New insights have been created into benefits beyond cardiovascular health. Modern milling and processing technologies have been developed to retain the nutritive value and functional properties of oats and to assure a consistent foundation for global health policies.

\section{Key words: Oats: Health: Agriculture: Policies}

In cooperation with C3 Collaborating for Health (London, UK) and the Quaker Oats Company (Chicago, IL), a subsidiary of PepsiCo Inc., an oats workshop was held on 8 and 9 May 2012 at the New York Academy of Medicine. This workshop assembled a group of international experts to discuss the potential health implications and applications of oats as part of a healthy diet. These diverse experts represented disciplines including, but not limited to, epidemiology, food regulation, nutrition and food science, grain breeding and plant genetics, food processing, medicine and public-health policy. This ensuing series addresses three important aspects pertinent to oats: a brief overview of the dynamics of oats; the spectrum of established and emerging research in agriculture and health; the options and opportunities for future applications of oats that extend beyond dietary fibre.

Oats (Avena sativa L.) are classified as a whole grain and are particularly high in soluble fibre, $\beta$-glucan, lipids, protein and specific micronutrients, as well as act as a unique source of polyphenols (avenanthramides) ${ }^{(1)}$. Whole grains are important dietary components of a healthy lifestyle, and the consumption of whole grains is advocated in the dietary guidelines and nutritional policies of many countries, including the USA (2010), Australia (2013), Canada (2011), Mexico (2006), and various countries in South America, throughout
Europe and Asia. The 2010 Dietary Guidelines for Americans advised the public to consume at least half of all grains as whole grains, which typically means at least three servings of whole grains daily ${ }^{(2)}$. This recommendation is based on evidence gathered in large part from observational studies on the effects of consumption of whole grains on chronic disease $e^{(3)}$ The predominance of evidence from observational and clinical research indicates that the regular consumption of at least three servings of whole grains ( $16 \mathrm{~g} /$ serving) - such as wheat, oats, rice, rye, barley, millet, quinoa and maize - may reduce the risk of developing several chronic diseases. Epidemiological data on whole grains alone are limited compared with data on mixtures of whole grain and bran or foods high in cereal fibre primarily because of varying definitions of what, and how much, was included in that food category ${ }^{(4)}$. The positive association between consumption of oats and reduced risk of CVD is represented in a variety of health claims in markets, such as the USA, Canada, Europe and Japan ${ }^{(5)}$.

Oats are an important but declining component of the more than 1400 million metric tonnes of mixed grains produced globally ${ }^{(6)}$. The USA is one of the largest producers of oats; the annual growth of this commodity has decreased from nearly 17 million metric tonnes (1960) to slightly less than 1 million metric tonnes (2012), and yet production within

*Corresponding author: R. Clemens, email clemens@usc.edu 
North America continues to represent approximately $16 \%$ of the world's supply ${ }^{(7)}$. The oat phenotypes are expressed in different environments and are evident by several physical and chemical characteristics ${ }^{(8)}$. Some of these characteristics include variations in $\beta$-glucan, protein and oil concentrations, whereas $\alpha$-tocopherol and avenanthramide concentrations appear to be consistent across genotypes grown in Idaho. Oat cultivars grow best in cool, moist or often described as moderate climates. This chiefly European and North American crop grows well in Russia, Canada and the USA ${ }^{(9)}$. Given the ongoing changes in climate, it is critical that oat varieties are developed that retain their nutrition and health benefits and tolerate temperature changes, requiring less water as well as being resistant to emerging plant pathogens, including barley yellow dwarf virus and Fusarium ${ }^{(10,11)}$.

Scientific evidence has transformed this centuries-old grain and global dietary staple to a pre-eminent nutritive source, with consumers increasingly moving towards consumption of whole grains as part of a more healthy diet. Recommendations from numerous dietary guidelines and nutrition policies encourage increased consumption of oats and other fibre-rich whole grains. Whether the potential health benefits of oats are linked to their high dietary fibre content (33\%) compared with other grains, their contribution of $\beta$-glucan that may lower cholesterol concentrations, or their myriad novel phytoconstituents, the preponderance of evidence supports oats' value to human health ${ }^{(1)}$.

For more than a century, new developments in oats science, technology, breeding and processing have yielded valuable insights. Recent clinical studies have investigated the effects of oat consumption on other health benefits beyond reducing cardiovascular risk such as diabetes, blood-pressure control, weight management and gastrointestinal health. In addition, new epidemiological data have become available, allowing analyses of the effect of consumption of oats on chronic disease, including cancer. Furthermore, laboratory studies have created valuable insights into the role of $\beta$-glucan and its ability to form viscoelastic gels, possibly an important mechanism in its mode of action that imparts satiety.

The transformation of raw oats to palatable products that deliver health benefits to consumers is critical. Changes in oat cultivar and improved food technologies that preserve the health attributes of oats and expand their application in food systems are important drivers to expand food applications and expand potential health benefits ${ }^{(12)}$. Important insights into such cultivars have been developed, and genome-sequencing efforts, as well as breeding programmes, are under way to select oat varieties with enhanced benefits ${ }^{(13)}$.

This series has been initiated to summarise the rapidly developing science and technology in oats and has brought together experts from several disciplines. It is dedicated to the spectrum of oats, from agriculture challenges and processing practices to their relationship with health and disease. It also discusses and accomplishes the following objectives:

1. Describe the physical and chemical characteristics of oats.

2. Review the most recent studies that elucidate the role of $\beta$-glucan in gel formation and discuss factors involved.
3. Review the nutritional composition of oats compared with other grains.

4. Discuss and systematically review the evidence associated with putative health benefits linked to oat consumption, such as reduced risk of CVD, including beneficial effects on blood pressure and LDL-cholesterol; bowel function, reducing inflammatory bowel disorders and irritable bowel syndrome; and reducing the risk of chronic disease such as diabetes and cancer, as well as possible effects for weight management.

5. Present the emerging evidence on oats and the human intestinal microbiome.

6. Describe opportunities for oat consumption in those with coeliac disease.

7. Outline the challenges associated with retaining the favourable characteristics of oats in a changing global environment.

8. Describe the global efforts in elucidating the oats genome as well as selection of cultivars and breeding programmes.

9. Summarise the preponderance of evidence that supports health claims and nutrition-policy development.

Finally, the aim of this series is to highlight the uniqueness of oats in the hope that this will raise awareness among scientists, health professionals, consumers and policymakers. Oats are increasingly under pressure from other crops such as soya and maize that yield higher financial return to farmers, because of a lack of subsidies and more attractive contract offers for other grains. Furthermore, there is an opportunity for oats to deliver health benefits in enjoyable forms of food to a wider array of consumers across the globe. Public-private partnerships may help to raise awareness among consumers and health professionals.

The evidence clearly demonstrates that oats are more than just a whole grain.

\section{Acknowledgements}

R. C. received an honorarium from Quaker Oats Company (a subsidiary of PepsiCo, Inc.) for attending the workshop in May 2012 to discuss the content of the supplement and to function as managing editor of the series of manuscripts. B. J.-W. v. K. is an employee of PepsiCo, Inc. The views expressed in this article are those of the author(s) and do not necessarily reflect the position or policy of PepsiCo, Inc. The article was jointly authored by R. C. and B. J.-W. v. K.

C3 Collaborating for Health is acknowledged for their efforts in organising the workshop held in New York in 2012 as well as their relentless work in administration, editing and organisational support in making this supplement possible.

This paper was published as part of a supplement to British Journal of Nutrition, publication of which was supported by an unrestricted educational grant from Quaker Oats Co. (a subsidiary of PepsiCo Inc.). The papers included in this supplement were invited by the Guest Editor and have undergone the standard journal formal review process. They may be cited. 
The Guest Editor to this supplement is Roger Clemens. The Guest Editor declares no conflict of interest.

\section{References}

1. Singh R, De S \& Belkheir A (2013) Avena sativa (oat) a potential neutraceutical and therapeutic agent: an overview. Crit Rev Food Sci Nutr 53, 126-144.

2. US Department of Agriculture and US Department of Health and Human Services (2011) 2010 Dietary Guidelines for Americans. http://www.cnpp.usda.gov/publications/dietaryguidelines/2010/policydoc/policydoc.pdf (accessed May 2013)

3. Jones JM \& Engleson J (2010) Whole grains: benefits and challenges. Annu Rev Food Sci Technol 1, 19-40.

4. Cho SS, Qi L, Fahey GC, et al. (2013) Consumption of cereal fiber, mixtures of whole grains and bran, and whole grains and risk reduction in type 2 diabetes, obesity, and cardiovascular disease. Am J Clin Nutr 98, 594-616.

5. Kennedy A, Stewart D \& Pavel A (2014) Beyond nutrition and agriculture policy: collaborating for a food policy. $\mathrm{BrJ}$ Nutr 112, S65-S74.

6. USDA (2013) World Agriculture Supply and Demand Estimates. http://www.usda.gov/oce/commodity/wasde/ latest.pdf (accessed May 2013).
7. USDA (2013) United States Oats Production by Year. http:// www.indexmundi.com/agriculture/?commodity $=$ oats\&country $=$ us\&graph $=$ production (accessed June 2013).

8. Peterson DM, Wesenberg DM, Burrup DE, et al. (2005) Relationships among argonomic traits and grain composition in oat genotypes grown in different environments. Crop Sci 45, 1249-1255.

9. Stewart D \& McDougall G (2014) Oat agriculture, cultivation and breeding targets: implications for human nutrition and health. BrJ Nutr 112, S50-S57.

10. Elsgaard L, Børgesen CD, Olesen JE, et al. (2012) Shifts in comparative advantages for maize, oat and wheat cropping under climate change in Europe. Food Addit Contam Part A Chem Anal Control Expo Risk Assess 29, 1514-1526.

11. Gräfenhan T, Patrick SK, Roscoe M, et al. (2013) Fusarium damage in cereal grains from Western Canada. 1. Phylogenetic analysis of moniliformin-producing Fusarium species and their natural occurrence in mycotoxin-contaminated wheat, oats, and rye. J Agric Food Chem 61, 5425-5437.

12. Decker EA, Rose D \& Stewart D (2014) Processing of oats and the impact of processing operations on nutrition and health benefits. BrJ Nutr 112, S58-S64.

13. Newell MA, Asoro FG, Scott MP, et al. (2012) Genome-wide association study for oat (Avena sativa $\mathrm{L}$.) $\beta$-glucan concentration using germplasm of worldwide origin. Theor Appl Genet 125, 1687-1696. 